\title{
A diet based on multiple functional concepts improves cognitive performance in healthy subjects
}

Anne Nilsson ${ }^{1 *}$, Juscelino Tovar ${ }^{2}$, Maria Johansson ${ }^{2}$, Karl Radeborg $^{3}$ and Inger Björck ${ }^{1,2}$

\begin{abstract}
Background: Disorders such as the metabolic syndrome (MetS), impaired glucose tolerance and diabetes, are associated with increased risk of cognitive decline. Also several of the individual key features that define the MetS, e.g. hypertension, impaired glucose regulation, dyslipidemia, obesity, and inflammation, are related to an increased risk of cognitive decline. Consequently, a diet that prevents metabolic disorders might be expected to prevent cognitive decline. The purpose of the present study was to, in overweight but otherwise healthy subjects, investigate effects on cognitive functions of a dietary regime combining multiple functional concepts potentially beneficial to risk markers associated with MetS. The purpose was in addition to evaluate cognitive performance in relation to results on cardiometabolic risk variables (BMI, blood pressure, glucose, insulin, cholesterol, triglycerides, free fatty acids, lipoprotein A-1 and B, hs-CRP, HbA1c, interleukin-6, TNF-a, and PAl-1).

Methods: Fourty-four healthy women and men (50-73 years, BMl 25-33, fasting glycemia $\leq 6.1 \mathrm{mmol} / \mathrm{L}$ ) participated in a randomized, controlled crossover intervention, comparing a multifunctional diet (active diet (AD)) including foods with a potential anti-inflammatory action, with a control diet (CD) devoid of the "active" components. Both diets were composed in close agreement with the Nordic dietary recommendations. Each diet was consumed during 4 wk, separated by a 4 wk washout period. Cognitive tests were performed at fasting and in the postprandial period after a standardized breakfast, after each diet period.

Results: In comparison with the CD, the AD improved performance in the Rey Auditory-Verbal Learning test (recognition test, $p<0.05$, ANOVA, $n=42$ ) and significantly improved performance in test of selective attention, which also included aspects of working memory $(p<0.05, n=40)$. Performance in cognitive tests was inversely associated with plasma concentrations of cardiometabolic risk markers (fasting cholesterol, blood glucose, blood pressure) and cardiovascular risk scores (Framingham and Reynols), and positivly associated with apolipoprotein A1 $(p<0.05)$.
\end{abstract}

Conclusions: The results indicate that diet characteristics may modulate cognitive performance. A relationship seems to exist between cardiometabolic risk markers and cognitive performance in apparently healthy subjects. The results provide additional motives for diet based prevention of metabolic disturbances related to the MetS.

Keywords: Cognitive performance, Cognitive decline, Diet and cognitive functions, Ageing, Metabolic disorders, Metabolic disease, Metabolic syndrome, Dietary prevention, Randomized controlled trial, Crossover design

\footnotetext{
* Correspondence: Anne.Nilsson@appliednutrition.Ith.se

${ }^{1}$ Department of Applied Nutrition and Food Chemistry, Lund University, P.O.

Box 124SE-221 00, Lund, Sweden

Full list of author information is available at the end of the article
} 


\section{Introduction}

Dietary prevention is increasingly recognized as a necessary strategy against the current epidemic of obesity and related metabolic disorders. Epidemiological studies and dietary interventions strongly support that high intake of whole grain foods and legumes are beneficial in the prevention and management of type 2 diabetes (T2DM), management of T1DM [1], and for weight control [2]. Foods with low glycemic index (GI) have further proven beneficial in the prevention and treatment of the metabolic syndrome (MetS), obesity, T2DM, and cardiovascular disease [3-6]. Other dietary measures, such as the inclusion of foods rich in omega-3 fatty acids [7] or polyphenols (e.g. berries) [8], have shown cardioprotective effects by improving blood lipid profile, lowering blood pressure, and positively affecting inflammatory markers $[7,9]$.

Obesity, insulin resistance and T2DM are closely associated with chronic inflammation, predominately in adipose tissue $[10,11]$. Interestingly, peripheral inflammatory cytokines can be actively transported across the blood-brain-barrier, or induce expression of cytokines in the brain; causing impairment of neuronal function $[12,13]$. Also, reduced insulin receptor signalling compromizes neuroplasticity; indicative of a link between chronic low grade inflammation, insulin resistance, and cognitive impairment $[14,15]$. T2DM and the MetS are associated with an increased risk of cognitive decline [16]. Consequently, a diet that prevents metabolic disorders might be expected to prevent an associated cognitive decline.

Certain foods or dietary patterns, e.g. polyphenol rich foods (e.g. berries and cocoa) [17-19], and low GI foods $[20,21]$, may improve cognitive functions and/or prevent cognitive decline. In prospective cohort- [22] and crosssectional [23] studies of middle aged and elderly populations, higher proportions of $n-3$ polyunsaturated fatty acids ( $n-3$ PUFA) in plasma were linked to a lower risk of cognitive decline, and a number of studies reveal that higher fish consumption promote better cognitive functions [24-28]. However, few studies have examined the possibilities to beneficially influence cardiometabolic risk markers and measures of cognitive performance by dietary means in apparently healthy subjects. Previously, we reported that an "active" dietary regime, gathering different anti-inflammatory food concepts, markedly reduced acknowledged cardiometabolic risk markers, as well as reduced predicted cardiovascular events in healthy overweighed subjects (BMI, mean \pm SEM: $28.5 \pm 0.3 \mathrm{~kg} / \mathrm{m}^{2}$ ) [29]. The diet was e.g. rich in low glycemic impact meals, antioxidant-rich foods, oily fish and rapeseed oil as sources of omega-3 fatty acids, viscous dietary fibers, soybeans, whole barley kernel products, almonds, stanols, and included also a probiotic strain. The rationale for investigating a healthy cohort was that the overall purpose of the study relates to dietary prevention, which in shorter interventions preferably is evaluated before manifest metabolic diseases have been developed.

The present paper is an extension to the study described above [29], now with the purpose to, in the same cohort, report the impact of the active diet on measures of cognitive functions. The purpose was in addition to evaluate cognitive performance in relation to results on cardiometabolic risk variables (BMI, blood pressure, glucose, insulin, cholesterol, triglycerides, free fatty acids, lipoprotein A-1 and B, hs-CRP, HbA1c, interleukin-6, TNF- $\alpha$, and PAI-1). Fourtyfour overweight but otherwise healthy subjects (5073 years, BMI $25-33 \mathrm{~kg} / \mathrm{m}^{2}$ ) participated in the study (randomized controlled crossover design). The active diet was compared with a control diet devoid of the active components/features. Each diet was consumed during four weeks with a four week washout period in-between.

\section{Subjects and methods}

Information regarding the subjects, diets (active and control), and study protocol for metabolic measurements are thoroughly described elsewhere (J Tovar et. al. 2012 [29]), and just briefly described in this paper. The present paper instead focuses on new data related to the cognitive aspects.

The study was approved by the Regional Ethical Review Board, Lund, Sweden (Dnr 593/2008).

\section{Subjects}

Inclusion criteria were age between 50 and 73 years, BMI $25-33 \mathrm{~kg} / \mathrm{m}^{2}$, and fasting plasma glucose concentration $\leq 6.1 \mathrm{mmol} / \mathrm{L}$. In total, 44 (36 females, $8 \mathrm{men}$ ) healthy subjects between 50 and 73 years of age (mean $63.3 \pm 0.8$ years) without any known medical condition or cognitive decline were included in the study. The subjects were overweight or slightly obese, but otherwise healthy (BMI (mean \pm SEM): $28.5 \pm 0.3 \mathrm{~kg} / \mathrm{m}^{2}$ ). BMI of two subjects were $25 \mathrm{~kg} / \mathrm{m}^{2}$, 34 subjects had BMI between $25-30 \mathrm{~kg} / \mathrm{m}^{2}$, and eight subjects had BMI $30-33 \mathrm{~kg} / \mathrm{m}^{2}$. More detailed description of subjects characteristics have been presented previously [29].

\section{Study protocol}

The study had a randomized, controlled, balanced crossover design. One active- and one control diet were included in the study (described below). Twenty subjects started with the active diet and 24 subjects with the control diet. Each diet period lasted four weeks, with a four-week washout period in-between. The whole trial included four clinical visits, one before and one after each diet phase. Cognitive tests were performed after each diet period, i.e. at visits no. two and four, whereas metabolic risk markers were determined at fasting at all four visits.

Before each intervention period (visits no. one and three), the participants performed test versions of the Selective Attention (SA) test and got thorough information 
regarding the Rey Auditory-Verbal Learning test (RAVLT) (the tests are described below). No specific screening for possible cognitive decline was carried out prior to the enrollment. However, performance in the pilot version of the SA-test at visit no. one was taken as a measure of the subjects' cognitive abilities to conduct the study in an adequate manner. In addition the participants underwent a medical examination at the first visit. All participants were considered qualified to participate in the study.

At the cognitive test days (visit no. two and four), the subjects arrived fasting in the morning between 7.30 am and 8.15 am (individually standardized). After resting for 15 minutes in a sitting position, physiological test parameters were determined, including weight, blood pressure, blood glucose, insulin, cholesterol (total cholesterol, LDL (low density lipoprotein), and HDL (high density lipoprotein)), triglycerides, free fatty acids, lipoprotein A-1 and B, hs-CRP (high-sensitivity C-reactive protein), HbA1c (glycated hemoglobin), inflammatory markers (IL-6 (interleukin-6), TNF- $\alpha$ (tumor necrosis factor alpha)), and PAI-1 (plasminogen activator inhibitor 1). A detailed description of the test variables and methods used have been presented previously [29]. The first SA-test was performed after obtaining the fasting metabolic test variables, and thereafter subjects were provided a standardized breakfast consisting of a white wheat bread (75.5 g) (Dollar Storfranska, Lockarps bakery, Malmö, Sweden) and apricot marmalade (27.7 g) (Ica, Sweden), corresponding to $55 \mathrm{~g}$ available carbohydrates in total. Water, $100 \mathrm{ml}$, and a plain cup of decaffeinated coffee or tea $(150 \mathrm{ml})$ were served with the bread. The breakfast was supposed to be consumed within $15 \mathrm{~min}$. Two of the participants were unable to eat the whole bread serving at the first experimental day (visit no. two). The leftovers were weighted and registered, and the subjects were served the same amounts of bread at the second experimental day (visit no. four). The cognitive tests were performed repeatedly up to $120 \mathrm{~min}$ after the start of the breakfast. A time schedule for execution of cognitive tests is presented in Table 1.

Table 1 Time schedule for execution of cognitive tests

\begin{tabular}{ccc}
\hline Time & SA-test & RAVLT-test $^{2}$ \\
\hline Fasting $(0 \mathrm{~min})^{1}$ & $X$ & \\
\hline $30 \mathrm{~min}$ & & \\
\hline $45 \mathrm{~min}$ & $X$ & $X$ \\
\hline $60 \mathrm{~min}$ & & \\
\hline $90 \mathrm{~min}$ & & \\
\hline $120 \mathrm{~min}$ & $X$ & \\
\hline
\end{tabular}

${ }^{1}$ The first SA-test was performed at fasting, directly prior to a standardised breakfast. ${ }^{2}$ The RAVLT took approximately $60 \mathrm{~min}$ to perform. SA selective attention, RAVLT Rey Auditory Verbal Learning Test.

\section{Test- and control diets}

The diets included (active diet and control diet) were non vegetarian, and designed in close agreement with the Nordic Nutrition Recommendations [30]. The active diet contained foods, food components, and food concepts, with documented potential to reduce sub-clinical inflammation and cardiometabolic risk, such as:

a) foods with high anti-oxidative capacity (anti-inflammatory effects [31], may improve blood pressure and blood lipids [8], suggested to be beneficial to cognitive functions [19]).

b) fatty fish (contain long chain n-3 PUFA, known to have anti-inflammatory and triglyceride-lowering properties [32,33], and are suggested to improve working memory capacity [34]). Rapeseed oil was included to provide additional n-3-PUFA.

c) prebiotic carbohydrates intrinsic in barley kernel products and whole grain rye foods, and products rich in dietary fibre from oat. Included was also bread supplemented with guar gum, which is a highly viscous fibre. Viscous fibre (in barley, oat, and guar gum) may lower the GI, and the indigestible carbohydrates included in the products can have prebiotic effects and improve glycaemic regulation, reduce satiety, and reduce inflammatory markers in a $10-14 \mathrm{~h}$ perspective $[35,36]$.

d) Low-GI foods/meals (reduce the risk of T2DM [37] and the MetS [38], reduce inflammatory tonus [39] and may be beneficial to cognitive functions $[20,21])$.

e) products that improve the blood lipid profile (soybeans, a margarine enriched in stanol esters, and dry almonds [40]).

In addition the active diet included a probiotic strain (Lactobacillus plantarum Heal19, DSM 15313) with health benefits on the gut microflora. The control diet contained a similar distribution of energy providing nutrients, but essentially lacked the active food components or food concepts.

The daily energy intake was based on gender, and supplied 2,500-2,600 Kcal/d for men and 2,000-2,100 $\mathrm{Kcal} / \mathrm{d}$ for women, including foods both from plant and animal origin. The nutritional profiles are presented in Table 2. The mean daily quantities of the different active foods or food components in the active diet, and the main functional properties that were considered for their inclusion, have been summarized in Table 3 . The products have been described in more detail previously [29].

Participants were provided with a 14-day menu plan which was repeated during the last two weeks. They had to follow the recipes in detail for breakfast, lunch, dinner and snacks (cooking procedures, and quantities by e.g. weighing the food ingredients). Since the purpose was that 
Table 2 Nutritional profiles of the control and active diet

\begin{tabular}{lccccc}
\hline & \multicolumn{2}{c}{ Control diet } & & \multicolumn{2}{c}{ Active diet } \\
\cline { 2 - 3 } & Women & Men & & Women & Men \\
\hline Energy (kcal/day)* & 2045 & 2570 & & 2100 & 2615 \\
\hline Protein (E\%) & 15 & 14 & & 19 & 18 \\
\hline Carbohydrate (E\%) & 56 & 55 & 51 & 50 \\
\hline Fat (E\%) & 29 & 30 & 31 & 31 \\
\hline Saturated fat (E\%) & 12.8 & 13.2 & 5.9 & 5.9 \\
\hline Monounsaturated fat (E\%) & 10.5 & 11.1 & 13.0 & 13.6 \\
\hline Polyunsaturated fat (E\%) & 3.6 & 3.7 & 8.2 & 8.4 \\
\hline$\omega-6$ fatty acids (E\%) & 2.9 & 3.1 & 4.2 & 4.3 \\
\hline$\omega-3$ fatty acids (E\%) & 0.8 & 0.8 & & 2.2 & 2.3 \\
\hline$\omega-6 / w-3$ ratio & 3.8 & 3.8 & 1.9 & 1.9 \\
\hline Dietary fiber (g/day) & 22 & 26 & 49 & 61 \\
\hline Cholesterol (mg/day) & 200 & 240 & 140 & 160
\end{tabular}

* Increased energy intake was prescribed for subjects that experienced weight loss during the initial weeks (Table 2 taken from Tovar et. al. [29]).

the study would be carried out under a constant weight, subjects had to weigh themselves at home once a week. If there was a discrepancy (up or down) by more than a $\mathrm{kg}$ compared with the beginning of a diet period, they were instructed to contact a nutritionist who was attached to the study in order to get help to adjust energy intake. They received a check list to fill in to check off every day that all active food components were consumed, and they had to make a note to describe any deviation from the menu. A limited amount of alcohol (30 and $37 \mathrm{~g}$ ethanol/wk for women and men, respectively), was allowed during the intervention period. The volunteers' ordinary coffee and tea drinking habits were maintained during the trial.

\section{Cognitive tests}

The rationale for the choice of cognitive tests was to include a broad variety of aspect of cognitive functions that are sensitive to metabolic disturbance. The SA-test covers several domains and cognitive aspects, e.g. working memory, attention and choice reaction time. The SA-test is of short duration, slightly less than $10 \mathrm{~min}$, and in this respect making it suitable for repeated testing. We have previously included the SA-test in investigations of food effects on cognitive functions, and investigations of relationships between cognitive functions and metabolic parameters (glucose tolerance), with good results [21,51]. The time points for the SA-test were chosen to cover several aspects with respect to glucose concentrations, and metabolism and its regulation; fasting stage, the postprandial peak increase in blood glucose, and later postprandial phase. The RAVLT took 1 hour to perform, making it difficult to repeat, however word lists have been used extensively with respect to investigations of cognitive effects of metabolic disorders (e.g. Hassenstab JJ et. al 2010 [52]).

\section{Selective attention (SA)}

The test was computerized, based on spatial perception, and primarily measured the ability to sustain a prolonged attention, and to control and split the attention to the entire picture on the computer screen $[21,51]$. The SA-test also included aspects of the working memory i.e. simultaneous temporary storing and processing of information. The SA was measured using a test made up of 96 pictures, each shown for two seconds on the screen. The pictures consisted of a square on a white background, divided into four smaller squares. One of the smaller squares was red, one was green, and two squares were uncolored (white),

Table 3 Proposed functional action and average content of active components in the active diet

\begin{tabular}{|c|c|c|c|}
\hline \multirow[t]{2}{*}{ Active components } & \multirow[t]{2}{*}{ Main functional role } & \multicolumn{2}{|c|}{ Contents in the AD (g/day) } \\
\hline & & Women & Men \\
\hline Soybean/soy protein & Cholesterol-lowering, anti-inflammatory $[40,41]$ & 21 & 25 \\
\hline \multicolumn{4}{|l|}{ VISCOUS FIBERS } \\
\hline b-glucans & Cholesterol- lowering, prebiotic, Gl-reducing $[21,42,43]$ & 5.8 & 6.2 \\
\hline Guar gum & & 5.6 & 6.7 \\
\hline Total & & 11.4 & 12.9 \\
\hline n-3 PUFA $(20: 5+22: 6)$ & Triglyceride-lowering, anti-inflammatory [32,33] & 2.4 & 3.0 \\
\hline Almonds & Cholesterol-lowering $[40,44]$ & 28 & 28 \\
\hline Plant stanols & Cholesterol-lowering $[40,45]$ & 2.0 & 2.7 \\
\hline Cinnamon & Antioxidant [46] & 3.0 & 3.0 \\
\hline Blueberries & Antioxidant, prebiotic [47] & 74.5 & 94.5 \\
\hline Vinegar & Gl -reducing [48] & 22.5 & 22.5 \\
\hline Probiotic & Anti-inflammatory [49] & $0.1\left(10^{10} \mathrm{CFU}\right)$ & $0.1\left(10^{10} \mathrm{CFU}\right)$ \\
\hline Whey protein* & Gl-reducing [50] & 4.3 & 4.3 \\
\hline
\end{tabular}

*Whey protein (10 g) was only consumed simultaneously with high Gl meals (potatoes, parsnip), 3 times per week. 
resulting in a total of 12 unique picture combinations. The subjects had to remember the positions of the colored squares, and to compare each new picture that emerged on the screen with the preceding one. Each time a new picture emerged, either the green, the red or none of the colored squares were positioned in the same position compared with the previous picture. Within two seconds, the subjects were supposed to indicate by pressing one of three different keys on the keyboard, which of the three possible alternatives that occurred for each new picture. The SA-test was performed at fasting and at 45, and 120 minutes after start of the standardized breakfast. The SA-test began with a short training session, and took approximately $10 \mathrm{~min}$ to perform. The test was scored with the number of correct responses (CR, total 95 credits) and for the reaction time (RT) needed to give the response (i.e. press one of the keys).

\section{The Rey Auditory-Verbal Learning test (RAVLT)}

The RAVLT [53] was used to measure aspects of learning and memory. The test was modified to avoid ceiling effects. A list of 30 common nouns (originally 15), were read to the subjects, separated by 2 seconds, in 5 consecutive trials. Each reading of a list was followed by an immediate free recall where the nouns were recalled and written down on paper within 2 minutes. Results after the 5 th reading measured best learning, and the mean of trials no. 1-5 was a measure of mean learning. In a 6th trial, an interference list of 30 new common nouns were presented, follow by an immediate recall (measuring proactive interference (PI) from list 1). In a 7th trial, the subjects were supposed to recall the first list, without a new reading (measuring retroactive interference (RI) from list 2). After a 20 minute break, in trial no. 8 , without an additional reading, the subjects were asked to again recall the first list (delayed recall). The next trial (trial no. 9) was a recognition test. The subjects were given a list with 100 nouns (modified from 50) of which 30 were from the first list, 30 from the second list, and 40 were new nouns. They were asked to, within 3 minutes, identify the 30 words that appeared on the first list. In the last trial (no. 10), the first list was presented on a paper in a different order than the original list (list no. one). They were asked to mark which words (10 nouns) that appeared fist on the original list, which words that appeared in the middle of the list (10 nouns) and which were in the end of the list (10 nouns) (memory of temporal order The test was scored for correct recalled nouns in trials no. $1-8$, mean learning (mean of trials no. 1-5), best learning (trial no, 5), recognition (trial no.9), and memory of temporal order (trial no. 10). The total RAVLT took approximately 60 minutes to perform.

\section{Calculations and statistical methods}

A power calculation was performed based on cardiometabolic test markers (plasma LDL-cholesterol and hs-CRP) in the parallel study [29]. Based on this power calculation it was decided to include 44 subjects. This is close to the number of subjects (40 subjects) that have been included in previous meal studies and interventions, using a corresponding SA-test [21,34]. The results are expressed as means \pm SEM. The influence of the active- and control diets on the cognitive tests was analyzed by repeated measures ANOVA at the test points, with order of diets, time point of the test, and diets as independent variables, and performance in cognitive tests as dependent variables. Statistical calculations were performed in Stat View 5.0 and SuperAnova 1.11. Significant differences in cognitive performance depending on diet sequence (cognitive test day one or two) were investigate with ANOVA (general linear model), in MINITAB Statistical Software (release 14; Minitab, Minitab Inc, State College, PA). Participants acted as their own control.

Multiple linear regression analysis was performed to examine relationships between cardiometabolic risk markers (independent variables) and performance in cognitive tests (dependent outcome variables), using STATA software package (release 10). A large number of cardiometabolic risk markers were determined (described above). To lower the number of risk markers, and to determine and avoid multicollinearity, pair-wise relationships were examined prior to regression analyses, using Pearson correlations in MINITAB Statistical Software (release 14; Minitab, Minitab Inc, State College, PA). Cardiometabolic risk markers with no tendency to be related with cognitive performance were eliminated. Pearson correlations in all possible pair-wise combinations of the cardiometabolic risk markers were performed. Five cardiometabolic risk markers (systolic blood pressure and fasting concentrations of: total cholesterol, insulin, glucose, ApoA1) were identified as non-linearly combined and included into the multiple regression models (model no. 1). Further backward stepwise analysis was conducted by checking the significance of the cardiometabolic risk markers and including in the model only those which were statistically significant (model 2). Furthermore, model 1 and model 2 were adjusted for age of the test subjects (model 3 and model 4, respectively). All models were tested for the normality of residuals. Data were tested for outliers, and no extreme or influential data were identified. In the case of a skewed distribution, variables were transformed accordingly before further analyses were performed (SA-tests: correct responses, and RAVLT: mean of trial 1-5 and trial 8 after both active- and control diet, and trial 7 after control diet, were analysed as their square values, trial no. 6 were analysed as there square roots, and cubic transformation were applied for trial no. 9 after both the active- and control diet). Regression analyses were based on data obtained from cognitive tests and risk markers determined at the same visits, generating separate 
regression analyses after the active diet and control diet, respectively.

Ten-year coronary heart disease risk was calculated with the Framingham Study equation [54], considering age, gender, total cholesterol, HDL-cholesterol, smoking and systolic BP values, and the Reynolds Risk Score [55], which also incorporates CRP values. Relations between Framingham- and Reynolds Risk Score and cognitive performance were evaluated with pairwise Pearson correlations.

Statistical evaluations of cardiometabolic risk variables are described elsewhere [29]. Values of $P<0.05$ were considered statistically significant.

\section{Results}

Two female subjects failed to accomplish the RAVLT, resulting in $n=42$ in this test (23 subjects started with the control diet and 19 subjects with the active diet). Two female subjects did not participate in the SA-test, resulting in $n=42$ in the SA-test (22 subjects started with the control diet and 20 subjects with the active diet). Two additional female subjects dropped out from SA-test no. 1 and SA-test no. $3(n=40,21$ subjects started with the control diet and 19 subjects with the active diet).

\section{Effects of diet on cognitive performance SA-TESTS}

No main effect depending on diet was observed in the SA-test when all test points were included in the statistical calculation. However, the results revealed significant time effects and interactions (see below) making it relevant to investigate performance in the SA-test at the different time points. Four weeks consumption of the active diet improved performance at $120 \mathrm{~min}$ in the SA-test (CR) in comparison with the control diet (Table 4$)(P<0.05$, ANOVA, $n=40)$. No significant differences in $\mathrm{RT}$ were detected (Table 5).

There was a significant time effect in the SA-test, showing improved performance with time at the test days, revealing increased $\mathrm{CR}$ at $45 \mathrm{~min}$ (73.7 \pm 1.6 credits) and $120 \mathrm{~min}$ (74.8 \pm 1.7 credits) compared with at fasting

Table 4 Correct responses in the SA-test after 4 weeks consumption of the active- versus the control diet

\begin{tabular}{|c|c|c|}
\hline & \multicolumn{2}{|c|}{ SA-test ${ }^{1}$} \\
\hline & Active diet & Control diet \\
\hline time 0 & $67.3 \pm 2.5$ & $65.6 \pm 2.5$ \\
\hline $45 \mathrm{~min}$ & $73.4 \pm 2.4$ & $74.0 \pm 2.1$ \\
\hline $120 \mathrm{~min}$ & $76.5 \pm 2.4$ & $73.1 \pm 2.5^{*}$ \\
\hline
\end{tabular}

Table 5 Reaction times in the SA-test after 4 weeks consumption of the active- versus the control diet ${ }^{1}$

\begin{tabular}{lcc}
\hline & \multicolumn{2}{c}{ SA-test (reaction time (msec) } \\
\cline { 2 - 3 } & Active diet & Control diet \\
\hline time 0 & $1320 \pm 20$ & $1320 \pm 21$ \\
\hline 45 min & $1182 \pm 21$ & $1230 \pm 21$ \\
\hline 120 min & $1202 \pm 23$ \\
\hline SA-test: selective attention test. & \\
Data are given as means per treatment \pm SEM, time $=0: \mathrm{n}=40$, time $=45: \mathrm{n}=$ \\
42, time $=120: \mathrm{n}=40$.
\end{tabular}

(66.5 \pm 1.8 credits) $(P<0.001)$, and decreased RT $(1321 \pm 14$, $1224 \pm 14$, and $1190 \pm 15 \mathrm{msec}$ at time 0,45 , and $120 \mathrm{~min}$ respectively, $(P<0.001)$. There were no main effects in performance of SA-tests (correct responses) depending on the consumption sequence of the diets (i.e. start with the active diet and consume the control diet in the second period (AC group, $n=20$ ), or vice-versa, starting with the control diet and consume the active diet in the last diet period (CA group, $n=24$ ). However, there was a significant diet"consumption sequence interaction $(P<0.001)$, revealing superior performance at all test points after the active diet compared with the control diet, when the active diet was consumed in the second diet period (SA-test $0 \mathrm{~min}$ : CR: $P<0.001$, RT: $P<0.01$; $45 \mathrm{~min}: \mathrm{CR}$ and RT: $P<0.01$, and 120 min: CR: $P<0.001$, RT: $P<0.01$ ). The mean of tests $0-120 \mathrm{~min}$ in the CA group was $77.1 \pm 2.6$ and $69.3 \pm 2.7$ credits and $1210 \pm 23$ and $1283 \pm 20 \mathrm{msec}$ after the active- and control diet, respectively. In the AC group, superior performance was achieved at $0 \mathrm{~min}$ and $45 \mathrm{~min}$ after the control diet, when control diet was consumed in the last diet period (SA-test 0 min: CR: $P<0.001$, RT: $P<0.05 ; 45$ min: CR: $P<0.01$ RT: $P<0.05)$. The mean of tests $0-45 \mathrm{~min}$ in the AC group was $72.6 \pm 3.8$ and $67.2 \pm 3.8$ credits and $1213 \pm 32$ and $1273 \pm 27 \mathrm{msec}$ after the control- and active diet, respectively. At $120 \mathrm{~min}$ in the AC group there was a significant improved RT after the control diet $(1154 \pm 32$ and $1209 \pm 34 \mathrm{msec}$ after the control- and active diet, respectively, $P<0.05$ ), but no differences in CR depending on diet $(71.5 \pm 4.1$ and $73.4 \pm 4.1$ credit after active- and control diet respectively, $P>0.05)$.

\section{RAVLT}

The trial in RAVLT measuring recognition (trial no. 9) was significantly improved after the active diet, in comparison with the control diet $(P<0.05$, ANOVA, $\mathrm{n}=42)$, (Table 6).

Effect of test occasion (cognitive experimental day one or two) Improved performances were observed at the second cognitive test day compared with the first test day in the SA-tests (mean test no. 1-3), both in CR and RT 
Table 6 Performance in the RAVLT after 4 weeks consumption of the active- versus the control diet ${ }^{1}$ RAVLT, trials no. 1-10

\begin{tabular}{lcc}
\hline & Active diet & Control diet \\
\hline 1: List 1 & $12.0 \pm 0.73$ & $11.3 \pm 0.64$ \\
\hline 2: List 1 & $16.8 \pm 0.73$ & $15.9 \pm 0.80$ \\
\hline 3: List 1 & $20.1 \pm 0.72$ & $20.0 \pm 0.75$ \\
\hline 4: List 1 & $21.8 \pm 0.71$ & $21.8 \pm 0.77$ \\
\hline 5: List 1 (best learning) & $22.7 \pm 0.68$ & $22.9 \pm 0.74$ \\
\hline 1-5: List 1 (mean learning 1-5) & $18.6 \pm 0.65$ & $18.4 \pm 0.69$ \\
\hline 6: List 2 (PI) & $9.3 \pm 0.62$ & $9.6 \pm 0.70$ \\
\hline 7: List 1 (RI) & $21.0 \pm 0.80$ & $20.7 \pm 0.86$ \\
\hline 8: 20 min pause. List 1 & $21.7 \pm 0.80$ & $21.7 \pm 0.95$ \\
\hline 9: List 3 (Recognition) & $28.0 \pm 0.51$ & $27.2 \pm 0.69^{*}$ \\
\hline 10: List 1 (Order of listed nouns) & $17.1 \pm 0.64$ & $16.0 \pm 0.59$
\end{tabular}

${ }^{1}$ RAVLT: The Rey Auditory-Verbal Learning test.

*: $p<0.05$ for the differences in performance in RAVLT no. 9 after the active diet in comparison to after the control diet. Data are given as means per treatment $\pm S E M, n=42$. $P$ l proactive interference, $R I$ retroactive interference.

(CR $68.3 \pm 2.3$ and $74.8 \pm 2.2$ credits at the first and second cognitive experimental day, respectively, $\mathrm{P}<0.05$; and RT: $1278 \pm 16.1$ and $1211 \pm 18.7 \mathrm{msec}$ at the first and second cognitive experimental day, respectively, $\mathrm{P}<0.05$ ).

In the RAVLT, subjects performed significantly better in trial no. 1-5 (mean) at the second test day in comparison to the first test day (trial 1-5 (mean value): $18.0 \pm 0.7$ and $19.4 \pm 0.6$ at the first and second cognitive experimental day, respectively, $\mathrm{P}<0.05)$. A similar effect of test day was seen in trials no. 7 (trial 7: firs test day $20.4 \pm 0.8$ and second test day $21.6 \pm 0.8, \mathrm{P}<0.05)$.

\section{Relations between cognitive performance and metabolic risk markers}

As previously have been reported [29], several metabolic risk markers were improved after four weeks intervention with the active diet, whereas no improvements were seen after the control diet. Briefly, the active diet significantly improved total serum cholesterol $(P<0.0001)$, LDL-cholesterol $(P<0.0001)$, triglycerides $(P<0.01)$, LDL/HDL-ratio $(P<0.0001$, apoB/apoA1-ratio $(P<0.0001)$, HbA1c $(P<0.01)$, hs-CRP $(P<0.05)$, and systolic blood pressure $(P<0.05)$. In addition, the Framingham and the Reynolds cardiovascular risk scores were both significantly reduced $(P<0.0001)$ after the active diet, with no change after the control diet [29]. Multiple regression analyses revealed that performance on the cognitive tests reported in this manuscript was significantly associated with several of the cardiometabolic risk markers; both after the active diet and the control diet (model 1 and 2, Tables 7, 8 and 9). Regression analyses (model 2) revealed that the number of CR in the SA-tests after both the active- and the control diet were inversely associated with concentrations of total cholesterol $(\mathrm{P}<0.05$, Table 7). The RT was positively related to total cholesterol (after the active diet, $\mathrm{P}<0.05)$ and systolic blood pressure (after active diet $(\mathrm{P}<0.01)$ and control diet $(\mathrm{P}<0.05)$ ). Adjusting for age in the SA-tests (CR and RT) did not affect relationships between metabolic risk markers and cognitive performance after the active diet, however, after the control diet age was a stronger predictor regarding number of CR (model 4: Coef. -131, Std- Err. 54.7, P $<0.05$, beta -0.35$)$ than total cholesterol (ns when adjusted for age). After the control diet both age (model 4: Coef. 9.2, Std. Err. 3.2, $\mathrm{P}<0.01$, beta 0.39 ) and systolic blood pressure (model 4: Coef. 2.5, Std. Err. 0.99, P $<0.05$, beta 0.34) were

Table 7 Associations between performance in the SA-test ${ }^{1}$ (CR and RT) ${ }^{2}$ and cardio-metabolic risk markers after the active- and the control diet, respectively, obtained with regression analyses (model 1 and model 2$)^{3}$

\begin{tabular}{|c|c|c|c|c|c|c|c|c|c|c|c|c|}
\hline \multicolumn{13}{|c|}{ SA-test } \\
\hline & \multicolumn{6}{|c|}{ Active diet } & \multicolumn{6}{|c|}{ Control diet } \\
\hline & \multicolumn{3}{|l|}{$C R$} & \multicolumn{3}{|l|}{ RT } & \multicolumn{3}{|l|}{$C R$} & \multicolumn{3}{|l|}{ RT } \\
\hline \multirow[t]{3}{*}{ MODEL 1: } & \multicolumn{3}{|l|}{$R^{2}: 0.28$} & \multicolumn{3}{|c|}{$R^{2}: 0.35$} & \multicolumn{3}{|l|}{$R^{2}: 0.21$} & \multicolumn{3}{|c|}{$R^{2}: 0.29$} \\
\hline & \multicolumn{3}{|c|}{ Adj- $R^{2}: 0.17$} & \multicolumn{3}{|c|}{ Adj- $R^{2}: 0.26$} & \multicolumn{3}{|c|}{ Adj- $R^{2}: 0.11$} & \multicolumn{3}{|c|}{ Adj- R2: 0.19} \\
\hline & \multicolumn{3}{|l|}{$P<0.05$} & \multicolumn{3}{|c|}{$P<0.01$} & \multicolumn{3}{|l|}{$P=0.1$} & \multicolumn{3}{|c|}{$P<0.05$} \\
\hline MODEL 2: & coef & (std Err) & beta & coef & (std Err) & beta & coef & (std Err) & beta & coef & (std Err) & beta \\
\hline Total- cholesterol & $-1048^{*}$ & $(416)$ & -0.37 & $53^{*}$ & $(22)$ & 0.32 & $-535^{*}$ & (244) & -0.33 & - & & \\
\hline ApoA1 & \multicolumn{3}{|l|}{-} & \multicolumn{3}{|l|}{-} & \multicolumn{3}{|l|}{ - } & \multicolumn{3}{|l|}{-} \\
\hline Systolic BP & \multicolumn{3}{|l|}{-} & $2.9^{* *}$ & $(0.97)$ & 0.40 & \multicolumn{3}{|l|}{-} & $2.6^{*}$ & $(1.1)$ & 0.36 \\
\hline Glucose & \multicolumn{3}{|l|}{-} & \multicolumn{3}{|l|}{-} & \multicolumn{3}{|l|}{-} & \multicolumn{3}{|l|}{-} \\
\hline Const. & 9968 & (1812) & & 638 & (153) & & 8344 & (1453) & & 898 & $(144)$ & \\
\hline
\end{tabular}


Table 8 Associations between performance in the RAVL (trials no. 1-10) and cardio-metabolic risk markers after the active diet, obtained with regression analyses (model 1 and model 2$)^{1}$

\begin{tabular}{|c|c|c|c|c|c|c|c|c|c|c|c|c|c|c|c|c|c|c|}
\hline \multicolumn{19}{|c|}{ RAVLT, active diet } \\
\hline & \multicolumn{3}{|c|}{$\begin{array}{l}\text { Mean trial no. 1-5 } \\
(n=42)\end{array}$} & \multicolumn{3}{|c|}{$\begin{array}{l}\text { Trial no. } 6 \\
(n=40)\end{array}$} & \multicolumn{3}{|c|}{$\begin{array}{l}\text { Trial no. } 7 \\
(\mathrm{n}=41)\end{array}$} & \multicolumn{3}{|c|}{$\begin{array}{l}\text { Trial no. } 8 \\
(n=41)\end{array}$} & \multicolumn{3}{|c|}{$\begin{array}{l}\text { Trial no. } 9 \\
(n=41)\end{array}$} & \multicolumn{3}{|c|}{$\begin{array}{l}\text { Trial no. } 10 \\
(n=39)\end{array}$} \\
\hline \multirow[t]{3}{*}{ MODEL 1.} & \multicolumn{3}{|l|}{$R^{2}: 0.32$} & \multicolumn{3}{|l|}{$R^{2}: 0.31$} & \multicolumn{3}{|l|}{$R^{2}: 0.30$} & \multicolumn{3}{|c|}{$R^{2}: 0.30$} & \multicolumn{3}{|l|}{$R^{2}: 0.24$} & \multicolumn{3}{|c|}{$R^{2}: 0.17$} \\
\hline & \multicolumn{3}{|c|}{ Adj- $R^{2}: 0.22$} & \multicolumn{3}{|c|}{ Adj- $R^{2}: 0.21$} & \multicolumn{3}{|c|}{ Adj- $R^{2}: 0.21$} & \multicolumn{3}{|c|}{ Adj- $R^{2}: 0.20$} & \multicolumn{3}{|c|}{ Adj- $R^{2}: 0.14$} & \multicolumn{3}{|c|}{ Adj- $R^{2}: 0.04$} \\
\hline & \multicolumn{3}{|l|}{$P<0.05$} & \multicolumn{3}{|l|}{$P<0.05$} & \multicolumn{3}{|l|}{$P<0.05$} & \multicolumn{3}{|c|}{$P<0.05$} & \multicolumn{3}{|l|}{$P=0.07$} & \multicolumn{3}{|c|}{$P=0.29$} \\
\hline MODEL 2. & coef & (std Err) & beta & coef & (std Err) & beta & coef & (std Err) & beta & coef & (std Err) & beta & coef & (std Err) & beta & coef & (std Err) & beta \\
\hline $\begin{array}{l}\text { Total- } \\
\text { cholesterol }\end{array}$ & - & & & - & & & - & & & - & & & - & & & - & & \\
\hline ApoA1 & $7.5^{*}$ & (3.1) & 0.32 & - & & & $9.6^{*}$ & (3.8) & 0.34 & $445^{* *}$ & $(157)$ & 0.30 & - & & & $7.9^{*}$ & $(3.3)$ & 0.36 \\
\hline Systolic BP² & $-0.10 * *$ & $(0.04)$ & -0.40 & - & & & $-0.11^{*}$ & $(0.04)$ & -0.37 & $-3.9^{*}$ & $(1.7)$ & -0.31 & - & & & - & & \\
\hline Glucose & - & & & $-0.44^{*}$ & $(0.28)$ & -0.37 & - & & & - & & & $-3576^{*}$ & $(1449)$ & -0.36 & - & & \\
\hline Const. & 21.6 & (6.6) & & 5.4 & $(0.98)$ & & 22.5 & $(8.0)$ & & 382 & (327) & & 42288 & $(7930)$ & & 6.0 & $(4.7)$ & \\
\hline
\end{tabular}

*: $p<0.05, * *: p<0.01 . \mathrm{n}=43$.

${ }^{1}$ Cardio-metabolic risk markers included in model 1 are: systolic blood pressure, fasting concentrations of total cholesterol, Apo A-1, insulin, and glucose. Model 2 includes test variables revealing significant effects on cognitive performance after step-wise, one-by-one elimination of non-significant test markers in model $1 .{ }^{2} B P$ blood pressure. 
Table 9 Associations between performance in the RAVL (trials no. 1-8) ${ }^{1}$ and cardio-metabolic risk markers after the control diet, obtained with regression analyses (model 1 and model 2$)^{2}$

\begin{tabular}{|c|c|c|c|c|c|c|c|c|c|c|c|c|}
\hline \multicolumn{13}{|c|}{ RAVLT, control diet } \\
\hline & \multicolumn{3}{|c|}{ Mean trial no. $1-5(n=43)$} & \multicolumn{3}{|c|}{ Trial no. $6(n=41)$} & \multicolumn{3}{|c|}{ Trial no. $7(n=42)$} & \multicolumn{3}{|c|}{ Trial no. $8(n=42)$} \\
\hline \multirow[t]{3}{*}{ MODEL 1.} & \multicolumn{3}{|c|}{$R^{2}: 0.18$} & \multicolumn{3}{|c|}{$R^{2}: 0.19$} & \multicolumn{3}{|l|}{$R^{2}: 0.30$} & \multicolumn{3}{|l|}{$R^{2}: 0.35$} \\
\hline & \multicolumn{3}{|c|}{ Adj- $R^{2}: 0.16$} & \multicolumn{3}{|c|}{ Adj- $R^{2}: 0.06$} & \multicolumn{3}{|c|}{ Adj- $R^{2}: 0.21$} & \multicolumn{3}{|c|}{ Adj- $R^{2}: 0.25$} \\
\hline & \multicolumn{3}{|c|}{$P<0.01$} & \multicolumn{3}{|c|}{$P=0.21$} & \multicolumn{3}{|c|}{$P<0.05$} & \multicolumn{3}{|l|}{$P<0.01$} \\
\hline MODEL 2. & coef & (std Err) & beta & coef & (std Err) & beta & coef & (std Err) & beta & coef & (std Err) & beta \\
\hline Total cholesterol & - & - & & - & & & - & & & - & & \\
\hline ApoA1 & $333 * *$ & $(109)$ & 0.43 & $1.3^{*}$ & $(0.51)$ & 0.37 & $489^{* *}$ & $(142)$ & 0.48 & $574^{* * *}$ & $(141)$ & 0.54 \\
\hline Systolic BP ${ }^{3}$ & - & - & & - & & & - & & & - & & \\
\hline Glucose & - & - & & - & & & - & & & - & & \\
\hline Const. & -143 & $(169)$ & & 1.0 & $(0.80)$ & & -282 & (220) & & -363 & (217) & \\
\hline
\end{tabular}

${ }^{1}$ Performance in trial no 9-10 did not reveal significant effects of metabolic risk markers, and the results are therefore not shown in the table.

${ }^{2}$ Cardio-metabolic risk markers included in model 1 are systolic blood pressure, fasting concentrations of total cholesterol, Apo A-1, insulin and glucose. Model 2

includes test variables revealing significant effects on cognitive performance after step-wise, one-by-one elimination of non-significant test markers in model 1.

${ }^{3} B P$ blood pressure.

${ }^{*}: p<0.05,{ }^{* *}: p<0.01,{ }^{* * *}: p<0.0001$.

positively related to the RT. The strongest predictors to performance in the RAVLT after the active diet were systolic blood pressure $(\mathrm{P}<0.05-0.01)$ and glucose concentrations $(\mathrm{P}<0.05)$ (inverse relationship), and Apo A-1 (positive relationship, $\mathrm{P}<0.05-0.01$ ), Table 8 . Concentration of Apo-A1 was also the strongest predictor to performance in the RAVLT after the control diet $(\mathrm{P}<0.05-0.001$, Table 9). Further adjusting for age did not affect the results after the active- or the control diet, with the exception that results in RAVLT trial no. 9 tended to be stronger associated with Apo A1 (model 4: Coef. 10604, Std. Err. 4420, P < 0.05, beta 0.34) than glucose concentrations (ns), that was the case without adjustment for age. Framingham- and the Reynolds cardiovascular risk scores to estimate 10-year cardiovascular risk were both highly correlated with performance in nearly all cognitive tests (Tables 10 and 11).

\section{Discussion}

The present study shows that four-week intervention with a diet that significantly improved cardiovascular risk variables also resulted in favorable effects on cognitive

Table 10 Pearson correlations between Reynold- and Framingham risk scores and performance in the SA-test (mean of tests no. 1-3) ${ }^{1}$

\begin{tabular}{|c|c|c|c|c|}
\hline \multirow{3}{*}{ Cardiovascular risk score } & \multicolumn{4}{|c|}{ SA-test. mean of tests $1-3$} \\
\hline & \multicolumn{2}{|c|}{ Correct response } & \multicolumn{2}{|c|}{ Reaction time } \\
\hline & $\begin{array}{l}\text { Active } \\
\text { diet }\end{array}$ & $\begin{array}{c}\text { Control } \\
\text { diet }\end{array}$ & $\begin{array}{l}\text { Active } \\
\text { diet }\end{array}$ & $\begin{array}{c}\text { Control } \\
\text { diet }\end{array}$ \\
\hline Reynold 10 years risk & -0.19 & -0.18 & $0.32^{*}$ & $0.46^{* *}$ \\
\hline $\begin{array}{l}\text { Framingham } 10 \text { years } \\
\text { risk }\end{array}$ & -0.03 & 0.07 & 0.16 & $0.33^{*}$ \\
\hline
\end{tabular}

${ }^{1}$ SA-test selective attention test.

${ }^{*}: p<0.05,{ }^{* *}: p<0.01$. functions. Consequently, improved cognitive performance was observed in the SA-test at $120 \mathrm{~min}$ post a standardized breakfast, and in the RAVLT at approximately $115 \mathrm{~min}$ (trial no. 9; recognition), after four weeks intervention with the "active" diet compared with the control diet. In this context, it must be noted that from a nutritional viewpoint both the active diet and the control diet were good diets, designed in close agreement with the Nordic Nutrition recommendations [30]. The improved performance in the SA-test and RAVLT (trial no. 9; recognition) were revealed late in the test session, indicative of reduced mental fatigue and/or increased learning capacity (the SA-test) during the test day after the active diet compared with the control diet.

Interestingly, in parallel to the improvements in cognitive functioning, the active diet improved several cardiometabolic risk markers connected to the MetS, e.g. lowered cholesterol concentrations, CRP, blood pressure, and improved measures of glucose regulation (HbA1c).

The purpose of this study was to evaluate cognitive effects of a mixed diet possessing metabolic advantageous. Thus, the study design does not allow any conclusions regarding effects of individual food components. However, the major inclusion criteria for the variety of foods and meals in the active diet were to achieve anti-inflammatory properties through several different food mechanisms [29]. One of the underlying purposes with combining several food concepts was to increase the possibility to include realistic amounts of each active food components, hence increasing compliance. When foods are investigated individually there is often a tendency to provide active test products in rather exaggerated amounts.

It is well established that metabolic disorders such as the MetS, impaired glucose tolerance, and T2DM are associated with increased risk of cognitive decline, e.g. 
Table 11 Pearson correlations between Reynold- and Framingham risk scores and performance in the RAVLT no. 1-9) ${ }^{1}$

\begin{tabular}{lcccccccccc}
\hline & \multicolumn{2}{c}{ Trial no.1-5 } & \multicolumn{2}{c}{ Trial no. $\mathbf{6}$} & \multicolumn{2}{c}{ Trial no. list $\mathbf{7}$} & \multicolumn{2}{c}{ Trial no. list $\mathbf{8}$} & Trial no. list $\mathbf{9}$ \\
\hline Cardiovascular risk score & Active diet & Control diet & Active diet & Control diet & Active diet & Control diet & Active diet & Active diet & Active diet & Control diet \\
\hline Framingham risk score & $-0.43^{* *}$ & $-0.46^{* *}$ & $-0.29^{\S}$ & $-0.38^{*}$ & $-0.42^{* *}$ & $-0.37^{*}$ & $-0.41^{* *}$ & $-0.41^{* *}$ & $-0.40^{* *}$ & $-0.42^{* *}$ \\
\hline Reynold risk score & $-0.55^{* * *}$ & $-0.55^{* * *}$ & $-0.33^{*}$ & $-0.37^{*}$ & $-0.48^{* *}$ & $-0.48^{* *}$ & $-0.52^{* * *}$ & $-0.52^{* * *}$ & $-0.43^{* *}$ & $-0.46^{* *}$
\end{tabular}

${ }^{1}$ RAVLT: The Rey Auditory-Verbal Learning test 1-9, no significant effects were detected in trial no. 10.

*: $p<0.05,{ }^{* *}: p<0.01,{ }^{* * *}: p<0.0001,{ }^{\S}: p<0.1$.

decrease in memory and executive functioning [56-58], information processing speed, and attention [16]. Also several of the individual key features that define the MetS, e.g. hypertension, impaired glucose regulation, dyslipidemia, obesity [59], and inflammation, are related to an increased risk of cognitive decline [60]. The results obtained in the present study indicate that cardiometabolic risk markers included in the MetS seem to be related to cognitive performance also in an apparently healthy cohort, suggesting that negative effects on cognitive functions may occur already in an early stage of metabolic deteriorations. Accordingly, the associations obtained in the present study can be described such that higher levels of metabolic risk markers (systolic blood pressure, total cholesterol, blood glucose) were related to worse performance in cognitive tests, meanwhile the opposite relations were obtained between cognitive performance and the potentially protective marker Apolipoprotein A1. Considering the relatively healthy study population, the results are certainly noteworthy. Additional striking results concerning relationships between cognitive performance and risk of cardiometabolic events, were the strong associations seen between cognitive performance and Framingham- and the Reynolds cardiovascular risk scores to estimate 10-year cardiovascular risk, which both were highly correlated (Pearson correlations) with performance in nearly all cognitive tests (Tables 10 and 11).

The test subjects in the present study can be considered to represent a comparatively healthy cohort. In contrast, other similar diet studies of the age matched population, that is $50-75$ years of age, typically include a hyperlipidemic study population $[40,61,62]$. A recent study revealed that the prevalence of the MetS in the Swedish population is between 10 to $16 \%$ among 50 -year-old women, 16 to $26 \%$ among 50-year-old men, and from 20 to $35 \%$ among the 60 -year-old men [63]. It was further revealed that only $5 \%$ of that population group had no risk factors related to the MetS. In the presently reported study, fifty-nine percent of the volunteers exhibited no MetS-feature, and only one could be classified as MetS-positive. Although it is widely recognized that T2DM and the metabolic syndrome is associated with an increased risk of cognitive decline, the results obtained in this study points towards a tight connection between metabolism and cognitive function also in a healthy study population. The results suggest the possibility of reversing cognitive decline by choice of diet, and highlight the importance of early dietary prevention. The dietary prevention strategy should preferably include dietary patterns aiming at lower sub-clinical inflammation and that beneficially affect several metabolic risk markers simultaneously; which was the purpose of the present study.

Due to the demographic profile of the population, the age-related socioeconomic burden of brain diseases, with or without dementia, is expected to markedly increase during the next two decades. Dementia constitutes a considerable part of these pathologies [64,65]. Of importance in this context is that the increased prevalence of cardiometabolic disorders, such as T2DM and MetS, can be expected to further increase the number of people suffering from cognitive decline. Several lifestyle characteristics, where diet plays an important role, are involved in the age related cognitive decline and dementia. For example, a diet rich in fat, especially of saturated type, has in longitudinal population-based studies (21 y [27] and 6 y [66] follow up), showed to be associated with poorer performance on a variety of cognitive tasks. Fat induced cognitive decline is probably mediated by increased insulin resistance [67]. On the contrary, prospective cohort studies indicate that diets rich in specific foods, such as e.g. fish [25], fruits [68], and polyphenol rich berries [69], may prevent age related cognitive decline.

In older adults with T2DM, it was noted that pharmacological interventions targeting glycemic control may improve aspects of cognitive functions, e.g. working memory, and improvements in cognitive tests were correlated with improvement in glycemic control [70]. Furthermore, in a two-year lifestyle intervention in T2DM with associated cognitive impairment, some aspects of cognitive function were improved to the same level as people with normal glucose tolerance. The intervention aimed to improve glucose control by including group exercise 2-4 times a week as well as nutritional education with recommendations of caloric intake, carbohydrate intake (55 energy\%), total fat intake (less than 30-35 energy\%), protein intake (10 to 15 energy\%), and dietary fiber intake (at least $30 \mathrm{~g} /$ day) [71]. Results obtained in the current study provide indications of the possibility of reversing a downward-sloping trend in cognitive performance by diet intervention also in an apparently healthy cohort.

The present investigation was performed in middleaged overweight volunteers under weight maintenance 
condition. However, the active diet was highly satiating, and a good proportion of the participants needed instructions by a nutritionist not to lose weight. Overweight and obesity are highly related to increased cardiovascular risk, suggesting a potential for additional cognitive improvements of the active diet if weight loss had been allowed.

The present study had certain limitations. One potential limitation was a possible practise effect, which was indicated by improved performance in the SA-test and some of the RAVLT at the second cognitive experimental day in comparison to the first experimental day. However, the study had a well-balanced design with respect to order of test diets, which probably eliminated this potential limitation.

\section{Conclusions}

The present study indicates that diet characteristics may modulate cognitive performance, and further, a relationship appears to exist between cardiometabolic risk markers and cognitive performance; also in apparently healthy subjects. The results provide additional motives for diet based prevention of metabolic disturbances related to the metabolic syndrome.

\begin{abstract}
Abbreviations
AD: Active diet; ApoA1: Apolipoprotein A1; Apo B: Apolipoprotein B BP: Blood pressure; CD: Control diet; hs-CRP: High sensitivity C-reactive protein; HBA1c: Glycated hemoglobin; HDL: High density lipoprotein; IL-6: Interleukin 6; LDL: Low density lipoprotein; MetS: Metabolic syndrome; PAI-1: Plasminogen activator inhibitor 1; RAVLT: The Rey Auditory-Verbal Learning test; RI: Retroactive interference; SA: Selective attention; T2DM: Type 2 diabetes mellitus; TNF-a: Tumor necrosis factor alpha.
\end{abstract}

\section{Competing interests}

The authors declare that they have no competing interests.

\section{Authors' contributions}

$A N, I B, J T$, and $M J$ were responsible for the study concept. AN was responsible for the design and coordination of the of the part of the study dealing with cognitive measurements. AN and JT conducted the research. KR and AN had the primary responsibility for statistical calculations, and AN and KR were responsible for the evaluations of the results on cognitive tests. AN and $\mathrm{IB}$ had primary responsibility for the final content, but all authors ( $A N, J T, K R, I B$, and $M J)$ were involved in the writing and evaluation of the paper. All authors read and approved the final manuscript.

\section{Acknowledgement}

This project has been funded by grants from the VINNOVA excellence centre Anti Diabetic Food Centre (AFC), Lund, Sweden.

\section{Author details}

${ }^{1}$ Department of Applied Nutrition and Food Chemistry, Lund University, P.O. Box 124SE-221 00, Lund, Sweden. ${ }^{2}$ Antidiabetic Food Centre, Lund University, SE-221 00, Lund, Sweden. ${ }^{3}$ Department of Psychology, Lund University, Lund, Sweden.

Received: 7 February 2013 Accepted: 11 July 2013

Published: 15 July 2013

\section{References}

1. Venn BJ, Mann Jl: Cereal grains, legumes and diabetes. Eur J Clin Nutr 2004, 58:1443-1461

2. O'Neil CE, Zanovec M, Cho SS, Nicklas TA: Whole grain and fiber consumption are associated with lower body weight measures in US adults: National Health and Nutrition Examination Survey 1999-2004. Nutr Res 2010, 30:815-822.

3. Brand-Miller JC: Glycemic load and chronic disease. Nutr Rev 2003, 61:S49-S55

4. Liu S, Willett WC, Stampfer MJ, Hu FB, Franz M, Sampson L, Hennekens CH, Manson JE: A prospective study of dietary glycemic load, carbohydrate intake, and risk of coronary heart disease in US women. Am J Clin Nutr 2000, 71:1455-1461.

5. Salmeron J, Ascherio A, Rimm EB, Colditz GA, Spiegelman D, Jenkins DJ, Stampfer MJ, Wing AL, Willett WC: Dietary fiber, glycemic load, and risk of NIDDM in men. Diabetes Care 1997, 20:545-550.

6. Salmeron J, Manson JE, Stampfer MJ, Colditz GA, Wing AL, Willett WC: Dietary fiber, glycemic load, and risk of non-insulin-dependent diabetes mellitus in women. JAMA 1997, 277:472-477.

7. Ebrahimi M, Ghayour-Mobarhan M, Rezaiean S, Hoseini M, Parizade SM, Farhoudi F, Hosseininezhad SJ, Tavallaei S, Vejdani A, Azimi-Nezhad M, et al: Omega-3 fatty acid supplements improve the cardiovascular risk profile of subjects with metabolic syndrome, including markers of inflammation and auto-immunity. Acta Cardiol 2009, 64:321-327.

8. Erlund I, Koli R, Alfthan G, Marniemi J, Puukka P, Mustonen P, Mattila P, Jula A: Favorable effects of berry consumption on platelet function, blood pressure, and HDL cholesterol. Am J Clin Nutr 2008, 87:323-331.

9. Zafra-Stone S, Yasmin T, Bagchi M, Chatterjee A, Vinson JA, Bagchi D: Berry anthocyanins as novel antioxidants in human health and disease prevention. Mol Nutr Food Res 2007, 51:675-683.

10. Wellen KE, Hotamisligil GS: Inflammation, stress, and diabetes. J Clin Invest 2005, 115:1111-1119.

11. Hotamisligil GS: Inflammation and metabolic disorders. Nature 2006, 444:860-867.

12. Banks WA, Farr SA, La Scola ME, Morley JE: Intravenous human interleukin-1alpha impairs memory processing in mice: dependence on blood-brain barrier transport into posterior division of the septum. J Pharmacol Exp Ther 2001, 299:536-541.

13. Jang $\mathrm{S}$, Johnson RW: Can consuming flavonoids restore old microglia to their youthful state? Nutr Rev 2010, 68:719-728.

14. Reagan LP: Insulin signaling effects on memory and mood. Curr Opin Pharmacol 2007, 7:633-637.

15. Huang CC, Lee CC, Hsu KS: The role of insulin receptor signaling in synaptic plasticity and cognitive function. Chang Gung Med J 2010, 33:115-125.

16. van den Berg E, Dekker JM, Nijpels G, Kessels RP, Kappelle LJ, de Haan EH, Heine RJ, Stehouwer CD, Biessels GJ: Cognitive functioning in elderly persons with type 2 diabetes and metabolic syndrome: the Hoorn study. Dement Geriatr Cogn Disord 2008, 26:261-269.

17. Lamport D, Dye L, Wightman J, Lawton CL: The effects of flavonoid and other polyphenol consumption on cognitive performance: a systematic research review of human experimental and epidemiological studies. Nutr Aging 2012, 1:5-25.

18. Krikorian R, Nash TA, Shidler MD, Shukitt-Hale B, Joseph JA: Concord grape juice supplementation improves memory function in older adults with mild cognitive impairment. Br J Nutr 2010, 103:730-734.

19. Krikorian R, Shidler MD, Nash TA, Kalt W, Vinqvist-Tymchuk MR, Shukitt-Hale $B$, Joseph JA: Blueberry supplementation improves memory in older adults. J Agric Food Chem 2010, 58:3996-4000.

20. Benton D, Ruffin MP, Lassel T, Nabb S, Messaoudi M, Vinoy S, Desor D, Lang $V$ : The delivery rate of dietary carbohydrates affects cognitive performance in both rats and humans. Psychopharmacology (Berl) 2003, 166:86-90.

21. Nilsson A, Radeborg K, Bjorck I: Effects on cognitive performance of modulating the postprandial blood glucose profile at breakfast. Eur J Clin Nutr 2012, 66:1039-1043.

22. Beydoun MA, Kaufman JS, Satia JA, Rosamond W, Folsom AR: Plasma n-3 fatty acids and the risk of cognitive decline in older adults: the Atherosclerosis Risk in Communities Study. Am J Clin Nutr 2007, 85:1103-1111.

23. Dullemeijer C, Durga J, Brouwer IA, van de Rest O, Kok FJ, Brummer RJ, van Boxtel MP, Verhoef P: $\mathrm{n} 3$ fatty acid proportions in plasma and cognitive performance in older adults. Am J Clin Nutr 2007, 86:1479-1485.

24. Dangour AD, Allen E, Elbourne D, Fletcher A, Richards M, Uauy R: Fish consumption and cognitive function among older people in the UK: baseline data from the OPAL study. J Nutr Health Aging 2009, 13:198-202.

25. Morris MC, Evans DA, Tangney CC, Bienias JL, Wilson RS: Fish consumption and cognitive decline with age in a large community study. Arch Neurol 2005, 62:1849-1853. 
26. van Gelder BM, Tijhuis M, Kalmijn S, Kromhout D: Fish consumption, n-3 fatty acids, and subsequent 5-y cognitive decline in elderly men: the Zutphen Elderly Study. Am J Clin Nutr 2007, 85:1142-1147.

27. Eskelinen MH, Ngandu T, Helkala EL, Tuomilehto J, Nissinen A, Soininen H, Kivipelto M: Fat intake at midlife and cognitive impairment later in life: a population-based CAIDE study. Int J Geriatr Psychiatry 2008, 23:741-747.

28. Nurk E, Drevon CA, Refsum H, Solvoll K, Vollset SE, Nygard O, Nygaard HA, Engedal K, Tell GS, Smith AD: Cognitive performance among the elderly and dietary fish intake: the Hordaland Health Study. Am J Clin Nutr 2007 86:1470-1478.

29. Tovar J, Nilsson A, Johansson M, Ekesbo R, Aberg AM, Johansson U, Bjorck I: A diet based on multiple functional concepts improves cardiometabolic risk parameters in healthy subjects. Nutr Metab (Lond) 2012, 9:29.

30. Nordic Council of Ministers: Nutrition Recommendations 2004: integrating nutrition and physical activity. 4th edition. Copenhagen: Nordic Council of Ministers; 2004.

31. Valtuena S, Pellegrini N, Franzini L, Bianchi MA, Ardigo D, Del Rio D, Piatti P, Scazzina F, Zavaroni I, Brighenti F: Food selection based on total antioxidant capacity can modify antioxidant intake, systemic inflammation, and liver function without altering markers of oxidative stress. Am J Clin Nutr 2008, 87:1290-1297.

32. Calder PC: $\mathrm{n}-3$ polyunsaturated fatty acids, inflammation, and inflammatory diseases. Am J Clin Nutr 2006, 83:1505S-1519S.

33. Skulas-Ray AC, Kris-Etherton PM, Harris WS, Vanden Heuvel JP, Wagner PR, West SG: Dose-response effects of omega-3 fatty acids on triglycerides, inflammation, and endothelial function in healthy persons with moderate hypertriglyceridemia. Am J Clin Nutr 2011, 93:243-252.

34. Nilsson A, Radeborg K, Salo I, Bjorck I: Effects of supplementation with n-3 polyunsaturated fatty acids on cognitive performance and cardiometabolic risk markers in healthy 51 to 72 years old subjects: a randomized controlled cross-over study. Nutr J 2012, 11:99.

35. Nilsson A, Granfeldt Y, Östman E, Preston T, Bjorck I: Effects of GI and content of indigestible carbohydrates of cereal-based evening meals on glucose tolerance at a subsequent standardised breakfast. Eur J Clin Nutr 2006, 60:1092-1099.

36. Nilsson AC, Östman EM, Holst JJ, Bjorck IM: Including indigestible carbohydrates in the evening meal of healthy subjects improves glucose tolerance, lowers inflammatory markers, and increases satiety after a subsequent standardized breakfast. J Nutr 2008, 138:732-739.

37. Dong JY, Zhang L, Zhang YH, Qin LQ: Dietary glycaemic index and glycaemic load in relation to the risk of type 2 diabetes: a meta-analysis of prospective cohort studies. Br J Nutr 2011, 106:1649-1654.

38. McKeown NM, Meigs JB, Liu S, Saltzman E, Wilson PW, Jacques PF: Carbohydrate nutrition, insulin resistance, and the prevalence of the metabolic syndrome in the Framingham Offspring Cohort. Diabetes Care 2004, 27:538-546.

39. Ceriello A, Davidson J, Hanefeld M, Leiter L, Monnier L, Owens D, Tajima N, Tuomilehto J: Postprandial hyperglycaemia and cardiovascular complications of diabetes: an update. Nutr Metab Cardiovasc Dis 2006, 16:453-456

40. Jenkins DJ, Kendall CW, Faulkner D, Vidgen E, Trautwein EA, Parker TL, Marchie A, Koumbridis G, Lapsley KG, Josse RG, et al: A dietary portfolio approach to cholesterol reduction: combined effects of plant sterols, vegetable proteins, and viscous fibers in hypercholesterolemia. Metabolism 2002, 51:1596-1604.

41. Azadbakht L, Kimiagar M, Mehrabi Y, Esmaillzadeh A, Hu FB, Willett WC: Soy consumption, markers of inflammation, and endothelial function: a cross-over study in postmenopausal women with the metabolic syndrome. Diabetes Care 2007, 30:967-973.

42. The US National Cholesterol Education Program, with lots of authors: Expert Panel on Detection, Evaluation, and Treatment of High Blood Cholesterol in Adults (2002). Third report of the national cholesterol education program (NCEP) expert panel on detection, evaluation, and treatment of high blood cholesterol in adults (adult treatment panel III) final report. Circulation 2002, 106:3143-3421.

43. Mitsou EK, Panopoulou N, Turunen K, Spiliotis V, Kyriacou A: Prebiotic potential of barley derived beta-glucan at low intake levels: a randomised, double-blinded, placebo-controlled clinical study. A Food Res Int 2010, 43:1086-1092.

44. Griel AE, Kris-Etherton PM: Tree nuts and the lipid profile: a review of clinical studies. Br J Nutr 2006, 96(Suppl 2):S68-78.
45. Esposito K, Giugliano D: Mediterranean diet and the metabolic syndrome: the end of the beginning. Metab Syndr Relat Disord 2010, 8:197-200.

46. Dugoua JJ, Seely D, Perri D, Cooley K, Forelli T, Mills E, Koren G: From type 2 diabetes to antioxidant activity: a systematic review of the safety and efficacy of common and cassia cinnamon bark. Can J Physiol Pharmacol 2007, 85:837-847.

47. Basu A, Du M, Leyva MJ, Sanchez K, Betts NM, Wu M, Aston CE, Lyons TJ: Blueberries decrease cardiovascular risk factors in obese men and women with metabolic syndrome. J Nutr 2010, 140:1582-1587.

48. Leeman M, Ostman E, Bjorck I: Vinegar dressing and cold storage of potatoes lowers postprandial glycaemic and insulinaemic responses in healthy subjects. Eur J Clin Nutr 2005, 59:1266-1271.

49. Lomax AR, Calder PC: Probiotics, immune function, infection and inflammation: a review of the evidence from studies conducted in humans. Curr Pharm Des 2009, 15:1428-1518.

50. Nilsson M, Holst JJ, Bjorck IM: Metabolic effects of amino acid mixtures and whey protein in healthy subjects: studies using glucose-equivalent drinks. Am J Clin Nutr 2007, 85:996-1004.

51. Nilsson A, Radeborg K, Bjorck I: Effects of differences in postprandial glycaemia on cognitive functions in healthy middle-aged subjects. Eur J Clin Nutr 2009, 63:113-120.

52. Hassenstab JJ, Sweat V, Bruehl H, Convit A: Metabolic syndrome is associated with learning and recall impairment in middle age. Dement Geriatr Cogn Disord 2010, 29:356-362.

53. Vaisman $\mathrm{N}$, Voet $\mathrm{H}$, Akivis A, Vakil E: Effect of breakfast timing on the cognitive functions of elementary school students. Arch Pediatr Adolesc Med 1996, 150:1089-1092.

54. Anderson KM, Wilson PW, Odell PM, Kannel WB: An updated coronary risk profile. A statement for health professionals. Circulation 1991, 83:356-362.

55. Ridker PM, Paynter NP, Rifai N, Gaziano JM, Cook NR: C-reactive protein and parental history improve global cardiovascular risk prediction: the Reynolds Risk Score for men. Circulation 2008, 118:2243-2251. 2244p following 2251.

56. Ruis C, Biessels GJ, Gorter KJ, van den Donk M, Kappelle LJ, Rutten GE: Cognition in the early stage of type 2 diabetes. Diabetes Care 2009, 32:1261-1265.

57. Cavalieri M, Ropele S, Petrovic K, Pluta-Fuerst A, Homayoon N, Enzinger C, Grazer A, Katschnig P, Schwingenschuh P, Berghold A, Schmidt R: Metabolic syndrome, brain magnetic resonance imaging, and cognition. Diabetes Care 2010, 33:2489-2495.

58. Lamport DJ, Lawton CL, Mansfield MW, Dye L: Impairments in glucose tolerance can have a negative impact on cognitive function: a systematic research review. Neurosci Biobehav Rev 2009, 33:394-413.

59. Taylor VH, MacQueen GM: Cognitive dysfunction associated with metabolic syndrome. Obes Rev 2007, 8:409-418.

60. Sparkman NL, Buchanan JB, Heyen JR, Chen J, Beverly JL, Johnson RW: Interleukin-6 facilitates lipopolysaccharide-induced disruption in working memory and expression of other proinflammatory cytokines in hippocampal neuronal cell layers. J Neurosci 2006, 26:10709-10716.

61. Jenkins DJ, Jones PJ, Lamarche B, Kendall CW, Faulkner D, Cermakova L, Gigleux I, Ramprasath V, de Souza R, Ireland C, et al: Effect of a dietary portfolio of cholesterol-lowering foods given at 2 levels of intensity of dietary advice on serum lipids in hyperlipidemia: a randomized controlled trial. JAMA 2011, 306:831-839.

62. Adamsson V, Reumark A, Fredriksson IB, Hammarstrom E, Vessby B, Johansson G, Riserus U: Effects of a healthy Nordic diet on cardiovascular risk factors in hypercholesterolaemic subjects: a randomized controlled trial (NORDIET). J Intern Med 2011, 269:150-159.

63. Welin L, Adlerberth A, Caidahl K, Eriksson H, Hansson PO, Johansson S, Rosengren A, Svardsudd K, Welin C, Wilhelmsen L: Prevalence of cardiovascular risk factors and the metabolic syndrome in middle-aged men and women in Gothenburg, Sweden. BMC Public Health 2008, 8:403.

64. Pugliatti M, Sobocki P, Beghi E, Pini S, Cassano GB, Altamura AC, Pozzoli S, Rosati G: Cost of disorders of the brain in Italy. Neurol Sci 2008, 29:99-107.

65. Sillanpaa M, Andlin-Sobocki $P$, Lonnqvist J: Costs of brain disorders in Finland. Acta Neurol Scand 2008, 117:167-172.

66. Morris MC, Evans DA, Bienias JL, Tangney CC, Wilson RS: Dietary fat intake and 6-year cognitive change in an older biracial community population. Neurology 2004, 62:1573-1579.

67. Greenwood CE, Winocur G: High-fat diets, insulin resistance and declining cognitive function. Neurobiol Aging 2005, 26(Suppl 1):42-45. 
68. Loef $\mathrm{M}$, Walach $\mathrm{H}$ : Fruit, vegetables and prevention of cognitive decline or dementia: a systematic review of cohort studies. J Nutr Health Aging 2012, 16:626-630.

69. Devore EE, Kang JH, Breteler MM, Grodstein F: Dietary intakes of berries and flavonoids in relation to cognitive decline. Ann Neurol 2012, 72:135-143.

70. Ryan CM, Freed MI, Rood JA, Cobitz AR, Waterhouse BR, Strachan MW: Improving metabolic control leads to better working memory in adults with type 2 diabetes. Diabetes Care 2006, 29:345-351.

71. Yamamoto N, Yamanaka G, Takasugi E, Ishikawa M, Yamanaka T, Murakami S, Hanafusa T, Matsubayashi K, Otsuka K: Lifestyle intervention reversed cognitive function in aged people with diabetes mellitus: two-year follow up. Diabetes Res Clin Pract 2009, 85:343-346.

doi:10.1186/1743-7075-10-49

Cite this article as: Nilsson et al: A diet based on multiple functional

concepts improves cognitive performance in healthy subjects. Nutrition \& Metabolism 2013 10:49.

\section{Submit your next manuscript to BioMed Central and take full advantage of:}

- Convenient online submission

- Thorough peer review

- No space constraints or color figure charges

- Immediate publication on acceptance

- Inclusion in PubMed, CAS, Scopus and Google Scholar

- Research which is freely available for redistribution 